\title{
Nasal instillation of nanoparticle-rich diesel exhaust particles slightly affects emotional behavior and learning capability in rats
}

\author{
Syunji Yokota', Hiromasa Takashima'1, Ryo Ohta², Yoshiaki Saito³, Takashi Miyahara', \\ Yuka Yoshida', Tsukasa Negura', Mika Senuma', Kenji Usumi ${ }^{3}$, Naoyuki Hirabayashi', \\ Takaho Watanabe ${ }^{4}$, Shinji Horiuchi'5, Yuji Fujitani ${ }^{6}$, Seishiro Hirano ${ }^{6}$ and Hidekazu Fujimaki ${ }^{6}$ \\ ${ }^{1}$ First Laboratory of Toxicology, ${ }^{2}$ Laboratory of Genetics, ${ }^{3}$ Laboratory of Pathology, ${ }^{4}$ Laboratory of Chemistry, \\ ${ }_{5}^{5}$ Animal Care, Hatano Research Institute, Food and Drug Safety Center, 729-5 Ochiai, Hadano, Kanagawa \\ 257-8523, Japan \\ ${ }^{6}$ Research Center for Environmental Risk, National Institute for Environmental Studies, 16-2 Onogawa, Tsukuba, \\ Ibaraki 305-8506, Japan
}

(Received December 6, 2010; Accepted February 23, 2011)

\begin{abstract}
In the present study, in order to reveal novel adverse effects of ultrafine particles (UFP) on the central nervous system, the effects of nanoparticle-rich diesel exhaust particles (NRDEP; count mode diameter, $21.45 \mathrm{~nm}$ ) on emotional behavior, learning capability and brain neurotransmitter levels were studied in rats by intranasal instillation (iNI). NRDEP (10 and $50 \mu \mathrm{g} / \mathrm{rat}$ ) was instilled into 2 -week old infant, male rats once a week for 4 weeks. Spontaneous motor activity measured was observed to be inverse to the dose level. In active avoidance tests using a shuttle box, NRDEP-treated animals showed a lower avoidance performance than control animals given air-instillation. The levels of dopamine and its metabolite (DOPAC) in the medial mammillary nucleus of the brain tended to be lower in the NRDEPtreated animals. From these results, although the effects of NRDEP by iNI on the emotionality and the brain neurotransmitter levels were not fully clear, the results obtained by avoidance testing suggested involvement of UFP in learning capability.
\end{abstract}

Key words: Olfactory bulb, Avoidance test, Spontaneous activity, Nanoparticle

\section{INTRODUCTION}

The health effects of ambient particulate matter (PM) in patients have been widely studied. Exposure of patients to PM increases respiratory disorders (Neas et al., 1995; Wong et al., 1999), cancer (Ito and Thurston, 1996) and arrhythmia (Rich et al., 2005). Also, it has been reported that a higher atmospheric black carbon concentration, a marker for traffic-generated particles, causes a decrease in cognitive function in children (Suglia et al., 2008). Furthermore, causes of olfaction deficits, endothelial hyperplasia in olfactory bulbs (OB), neuronal accumulation of particles and presage of Alzheimer disease have been observed in children and young adults inhabiting urban areas (Calderón-Garcidueñas et al., 2010).

Recently, the proinflammatory effects of nanoparticles, developed as industrial materials, on the brain have been studied (Oberdörster et al., 2005; Win-Shwe et al., 2006, 2008a; Wang et al., 2008a, 2008b). It has been suggested that particles with diameters less than $100 \mathrm{~nm}$ are easily translocated into the brain (Mistry et al., 2009; Liu et al., 2009) and impair OB and cerebral tissues, where their injurious effects are due mainly to their oxidative activity (Win-Shwe et al., 2006, 2008a; Wang et al., 2008b). Therefore, it has been considered that translocation of nanoparticles into the brain may have adverse effects on the central nervous system (CNS) (Wang et al., 2008b; Win-Shwe et al., 2008b).

The high number of atmospheric ultrafine particles (UFP), with diameters less than $100 \mathrm{~nm}$ and mainly exhausted from diesel engines (Biswas and $\mathrm{Wu}, 2005$ ), their adverse effects have recently become a focus of attention on in advanced counties. In advanced countries, although the exhaust of larger particles, such as PM 2.5

Correspondence: Syunji Yokota (E-mail: yokota.s@fdsc.or.jp) 
(PM with diameters less than $2.5 \mu \mathrm{m}$ ) from motor vehicles was strongly regulated, that of smaller particles, such as UFP, has not yet been regulated. Since diesel exhaust particles contain various metals and chemicals, nanoparticles also show a strong injurious activity via production of oxygen radicals (Vogl and Elstner, 1989). Win-Shwe et al. (2008b) reported that co-exposure of mice to nanoparticle-rich diesel exhaust and lipoteichoic acid caused dysfunction of spatial learning, an increase in levels of gene expression related to the memory function, and inflammation in the hippocampus. Taking these reports together, it is worthwhile investigating the effects of nanoparticle-rich diesel exhaust particles (NRDEP) on the CNS in experimental animals by intranasal instillation (iNI).

Since the "Miami Declaration" from the "G8 Environment Ministers Meeting on Children's Environmental Health," held in 1997, recommended, "the effects of environmental pollutants should be evaluated in young-aged animals" (1998), the experiment was designed to be able to evaluate the influence on young animals. Therefore, in the present study, NRDEP was administered to animals at an early stage of life, i.e., infancy, and its effects on emotional behavior, learning capability and neurotransmitter levels in the brain were evaluated during growth.

\section{MATERIALS AND METHODS}

\section{Reagents}

3,4-dihydroxyphenylacetic acid (DOPAC), 5-hydroxyindole acetic acid (5-HIAA), dopamine (DA), homovanillic acid (HVA), noradrenalin (NA) and serotonin (5-HT) were purchased from Sigma (St. Louis, MO, USA) and used as standard substances of liquid chromatograph. Tris(hydroxymethyl)amino-methane (Tris) were purchased from Sigma. 5-perchloric acid and polyoxyethylene sorbitan monooleate (Tween80) were purchased from Wako (Tokyo, Japan). Protein Assay kit was purchased from Bio-Rad (Hercules, CA, USA). Sodium pentobarbital was purchased from Tokyo Kasei (Tokyo, Japan).

\section{NRDEP collection and preparation for nasal instillation}

NRDEP was collected at the National Institute for Environmental Studies Japan (NIES: Ibaraki, Japan). An 81-diesel engine (J08C, Hino Motors, Tokyo, Japan) was run under steady-state conditions (speed: 2,000 rpm; engine torque: $0 \mathrm{Nm}$; diesel fuel: JIS No. 2) for $7 \mathrm{hr}$. These conditions generated nanoparticle-rich exhaust (particle concentration, $3.51 \times 10^{7}$ counts $/ \mathrm{ml}$; count mode diameter \pm S.D., $21.45 \pm 1.46 \mathrm{~nm}$ ) (Fujitani et al., 2009). Particles were collected at approximately $10 \mathrm{~m}$ from the engine with a dilution ratio of $8\left(55 \mathrm{~m}^{3} / \mathrm{min}\right)$ on dichloromethane-washed, gold discs $(25 \mathrm{~mm}$ in diameter, $0.025 \mathrm{~mm}$ in thickness) electrostatically (-27 kvolts) at a flow rate of 20 1/min using a sampler (SSPM-100, Shimadzu, Kyoto, Japan). The composition by weight of NRDEP collected at the dilution tunnel was analyzed at NIES, and the main elements of NRDEP with diameters less than $100 \mathrm{~nm}$ were organic carbon (86\%) and elemental carbon (12\%). Furthermore, the sum of metals, including $\mathrm{Fe}, \mathrm{Co}, \mathrm{Ni}$ and $\mathrm{Zn}$, was $0.14 \%$. In addition, $\mathrm{Mg}, \mathrm{Ti}, \mathrm{V}, \mathrm{Cr}, \mathrm{Mn}, \mathrm{Cu}$ and $\mathrm{Pb}$ were not detectable. The average single particle weight for particles less than $470 \mathrm{~nm}$ in diameter was calculated at NIES, and was $0.03 \mathrm{fg}$.

Seven gold discs with NRDEP (totally $4.271 \mathrm{mg}$ ) were provided and stored in refrigerator $\left(-30^{\circ} \mathrm{C}\right)$. Two days before first instillation, NRDEP was dispersed from the discs into the vehicle $(0.05 \%$ Tween 80 -saline $)$ using an ultrasonic water bath (US-2, SND, Nagano, Japan) under ice-cold conditions for $10 \mathrm{~min}$ per disc. Finally, $1 \mathrm{mg} / \mathrm{ml}$ of suspended NRDEP (approximately $4.2 \mathrm{ml}$ in volume) was obtained, and then, $300 \mu \mathrm{l}$ of the suspension was diluted 5 fold with the vehicle $(0.2 \mathrm{mg} / \mathrm{ml})$. These NRDEP suspensions were divided into 4 tubes of each, and were stored in a refrigerator $\left(-30^{\circ} \mathrm{C}\right)$ until of use. At the administration of NRDEP, the suspensions were sonicated for $10 \mathrm{~min}$, before of use. Aggregation of NRDEP in suspension was observed by scanning electron microscope and it was confirmed that NRDEP formed aggregates in the range of approximately $100-200 \mathrm{~nm}$ in length.

In addition, 2 fresh gold discs without NRDEP were immersed in the vehicle and were sonicated for $10 \mathrm{~min}$. The liquid obtained was administered to control animals to evaluate the biological effects of the vehicle.

\section{Animals and breeding}

The present study was carried out in accordance with the Instructions of the Committee for Ethical Usage of Experimental Animals in Hatano Research Institute.

Fifty infants, male Sprague-Dawley rats at 12 days of age (weighing 24.7-33.7 g) were purchased from Atsugi Breeding Center, Charles River Japan (Kanagawa, Japan), with 5 foster mothers. The animals were divided into 5 sets, each comprising 10 infants and a foster mother, and each set was housed in a single polycarbonate cage with bedding chips ( $35 \times 40 \times 18 \mathrm{~cm}$ in width $\mathrm{x}$ depth $\mathrm{x}$ height) until the animals were 5 weeks of age. After that, at 6 weeks of age, the animals were individually housed in grid-floored, stainless steel cages $(22 \times 27 \times 19 \mathrm{~cm})$. To reduce the stress from the environmental changes, breeding condition during administration period (2-5 weeks of age) was not changed including group breeding and cage size. 
The effects of nanoparticle-rich diesel exhaust particles on CNS

\section{Grouping and iNI}

Each set of 10 pups was divided into 5 groups of 2 pups each. Each of three groups were treated with the vehicle, $10 \mu \mathrm{g}$ of NRDEP or $50 \mu \mathrm{g}$ of NRDEP, respectively (i.e., using $25 \mu 1$ of $0.05 \%$ Tween 80 -saline for each nostril, totally $50 \mu 1$ were instilled by Eppendorf ${ }^{\circledR}$ micropipette); one group was given sham treatment (i.e., instillation of $25 \mu \mathrm{l}$ of air into each nostril for the estimation of the effects by vehicle); and remained 2 pups of each were used for histopathological examination at 5 weeks of age (i.e., satellite group). For this examination, the 10 animals in the satellite group were treated with air (3 animals), vehicle (3 animals) or $50 \mu \mathrm{g}$ of NRDEP (4 animals).

\section{Summary of the study protocol}

From 14 days (i.e., 2 weeks) of age, the animals were treated with air (sham treatment), vehicle, $10 \mu \mathrm{g}$ of NRDEP or $50 \mu \mathrm{g}$ of NRDEP by once per week, for 4 weeks. The day following the last treatment, the animals in the satellite group were used for histopathological examination. The behavioral tests of the 10 animals remaining in each treatment group (i.e., $50 \mu \mathrm{g}$ of NRDEP, $10 \mu \mathrm{g}$ of NRDEP, vehicle, and sham) were examined from 6 weeks to 11 weeks of age. At 12 weeks of age, half (i.e., 5) of the animals in each treatment group were used for pathological examination of the brain. Finally, the 5 animals remaining in each treatment group were used for the measurement of neurotransmitter levels in brain areas and organ weights. In addition, no abnormalities in general condition was observed in any animals used during the study. Also, no significant differences in body weight changes and organs weight were observed between groups.

\section{Histopathological examination of brain in the satellite animals}

The day following the last treatment (5 weeks of age), the animals in the satellite group were sacrificed by exsanguination under anesthesia $(60 \mathrm{mg} / \mathrm{kg}$ of pentobarbital, PB; i.p.). Polyethylene catheter was passed into the aorta via apex of left ventricle of the heart, and axillary vein was cut bilaterally. After an initial perfusion with cacodylate-buffered saline solution for $1 \mathrm{~min}$, the arteries excepting of carotid artery were ligated. Then, a mixture of $0.1 \mathrm{M}$ cacodylate-buffered $2 \%$ paraformaldehyde and 1.25 glutaraldehyde ( $\mathrm{pH} 7.4$ ) was perfused at room temperature for $10 \mathrm{~min}$. Perfusion was carried out at a pressure of 700-800 $\mathrm{mmH}_{2} \mathrm{O}$. After fixation, the brain, including the olfactory bulbs, was isolated, and then small blocks were fixed with $0.1 \mathrm{M}$ cacodylate-buffered $2 \%$ osmium tetroxide and embedded in epoxy resin. Semith- in sections were stained with toluidine blue and observed microscope. Ultrathin sections stained with uranyl acetate and lead citrate were observed with an electron microscope (H-7100, Hitachi, Tokyo, Japan). Additionally, the olfactory bulbs were examined by energy dispersive X-ray spectroscopy (H7650, Hitachi and EMAX, Horiba, Kyoto, Japan).

\section{Measurement of spontaneous motor activity by Supermex}

The horizontal (ambulation) and vertical (rearing) spontaneous motor activity of animals at 6 weeks of age was measured automatically by infrared pyroelectric sensors (Supermex, Muromachi, Tokyo, Japan). Animals were placed individually in an acrylic box $(33 \times 44 \times 32 \mathrm{~cm})$ at 13:00. Then, the measurement was started, and their ambulation and number of times rearing were cumulatively counted every $30 \mathrm{~min}$ for $24-\mathrm{hr}$. Feeding and drinking were taken ad libitum during the test.

\section{Learning ability estimated by shuttle box avoidance test}

At 9 weeks of age, animals were subjected to a shuttle box avoidance test (Unicom Inc., Chiba, Japan), comprising two compartments $(50 \times 20 \times 25 \mathrm{~cm})$. For each trial, a $3 \mathrm{sec}$ conditioning stimulus (CS), comprising a buzzer and a light, was followed by $3 \mathrm{sec}$ of unconditioned stimulus, comprising the CS plus a $1.0 \mathrm{~mA}$ electric current to the grid floor. The number of responses in which the animal moved to the other side during the CS was recorded. Sixty conditioning trials, separated by $30 \mathrm{sec}$ inter-trial intervals, were given daily for 3 consecutive days.

\section{Histopathological examination and brain dissection}

After behavioral examination, half (i.e., 5) of the animals in each treatment group were sacrificed under anesthesia ( $60 \mathrm{mg} / \mathrm{kg}$ of PB, i.p.), at 12 weeks of age. Brain, including $\mathrm{OB}$, heart, lungs, liver, kidneys, spleen and testes were isolated and immersed in $10 \%$ formaldehyde-PBS for histopathological examination by light microscopy.

The remaining 5 animals in each treatment group were sacrificed by decapitation at 14 weeks of age, and the brain was immediately isolated and placed on ice. OB was quickly isolated and frozen. In accordance with the methods described by Palkovits and Brownstein (1983), brain areas were isolated. The brain was placed on a brain slicer (RB-AL1-C, Muromachi), and frozen with dry ice. Then, the brain was coronally dissected in slices $1.0 \mathrm{~mm}$ in thickness using a razor, and the lateral hypothala- 
mus (LH), medial amygdaloid nucleus (Me), ventromedial hypothalamic nucleus (VMH) and medial mammillary nucleus (MM) were punched out in accordance with a brain atlas (Paxinos and Watson, 1998). The samples were frozen and stored in a deep freezer $\left(-90^{\circ} \mathrm{C}\right)$. In addition, liver, kidneys, adrenal glands, spleen and testes were isolated and were weighed.

\section{Monoamines and metabolites level in brain areas}

A frozen sample of a brain area was thawed and homogenized in $200 \mu \mathrm{l}$ of perchloric acid $(0.1 \mathrm{M}$, $\mathrm{pH}$ 3.0). Then, the sample was centrifuged (10,000 $\mathrm{g} \times 15$ min at $\left.4{ }^{\circ} \mathrm{C}, \mathrm{CF}-15 \mathrm{R}\right)$, and the supernatant and pellet were separated. Then, the supernatant $(100 \mu 1)$ was injected into a high-performance liquid chromatography (HPLC) system (System-6, Shimadzu), and the amounts of NA, DA, DOPAC, HVA, 5-HT and 5-HIAA were measured with an electrochemical detector (3005, Shiseido, Tokyo, Japan). The pellet was resuspended in $100 \mathrm{mM}$ Tris- $\mathrm{HCl}$ ( $\mathrm{pH} 8.0$ ), and the concentration of protein was measured by Bradford protein assay with Bio-Rad Protein Assay Kit.

\section{Statistical Analysis}

Values are expressed as the means \pm S.E.M. of the 10 animals in each treatment group, except for organ weights and monoamine neurotransmitter levels in brain areas $(\mathrm{n}=5)$. Two-way ANOVA was used, with Bonferroni's correction to control for multiple comparisons (Prism 4.0; Graph Pad, San Diego, CA, USA). Significance levels ( $p$ ) less than 0.05 were considered to be significant. Fischer's exact probability test was used to compare incidences between two groups.

\section{RESULTS}

\section{Spontaneous motor activity}

A significantly higher spontaneous motor activity in the ambulation was observed in the first several hours of the light period (13:00-16:00) of the group treated with $10 \mu \mathrm{g}$ of NRDEP (lower panel of Fig. 1). In these animals, activity in the rearing also tended to be higher (upper panel of Fig. 1). Furthermore, the animals in the group treated with $10 \mu \mathrm{g}$ of NRDEP displayed greater activity in rearing during the dark period (19:00-07:00), although no statistically significant differences were observed between the groups. Conversely, the animals in the group treated with $50 \mu \mathrm{g}$ of NRDEP displayed slightly lower activity in both directions than those in the groups given sham treatment or treated with the vehicle.

\section{Shuttle box avoidance test}

The mean daily avoidance rate of each group is shown in the upper panel in Figs. 2 (A, B and C), and scatter plots of individual avoidance rates in each group are shown in the lower panel in Figs. 2 (D, E and F). The mean daily avoidance rate in the group given sham treatment improved day by day Figs. 2 (A, B and C), accompanied by a reduction in decentralization in the individual avoidance rates in the animals Figs. 2 (D, E and F). The mean daily avoidance rate in the vehicle group also improved day by day, although complete failure in the avoidance task was observed in 1 animal during the 3 days Figs. 2 (D, E and F). The animals in the NRDEPtreated groups showed a suppression of daily improvement in the mean daily avoidance rate Figs. 2 (A, B and C). Especially, the mean daily avoidance rate in the group given $50 \mu \mathrm{g}$ of NRDEP mostly did not improve during the 3 days. Also, a reduction of decentralization of individual avoidance rates in the animals was not observed Figs. 2 (D, E and F). Because a large decentralization of mean daily avoidance rates was observed in the animals treated with NRDEP, the number of animals in the first quartile (Q1) was counted, and it appeared that almost all the animals below Q1 were NRDEP-treated animals (Table 1).

\section{Histopathological examination}

In the animals subjected to pathological examination on the day following the last day of treatment (5 weeks of age), an increased number of corpuscles densely stained with toluidine blue was observed by light microscopy in the glomerulus of $\mathrm{OB}$ in the animals treated with $50 \mu \mathrm{g}$ of NRDEP. By transmission electron microscopy, electron dense lamellar bodies were observed in the microglial cells of the glomerulus (Fig. 3A). However, changes were very slight. Also in the area close to the glomerulus, a marked accumulation of electron dense granules with diameters of approximately $20 \mathrm{~nm}$ was observed in the axonal cytosole (Fig. 3B). Examination using energy dispersive X-ray spectroscope revealed large granules containing phosphorus (Fig. 3C). In addition, no marked abnormalities were observed in the brain and nasal cavity of animals treated with $50 \mu \mathrm{g}$ of NRDEP. Also, no abnormalities were observed in the heart, liver, kidneys and spleen in NRDEP-treated animals at 9 weeks of age by light microscopy. In addition, no changes related to the deposition of NRDEP in the lung were observed. 
The effects of nanoparticle-rich diesel exhaust particles on CNS

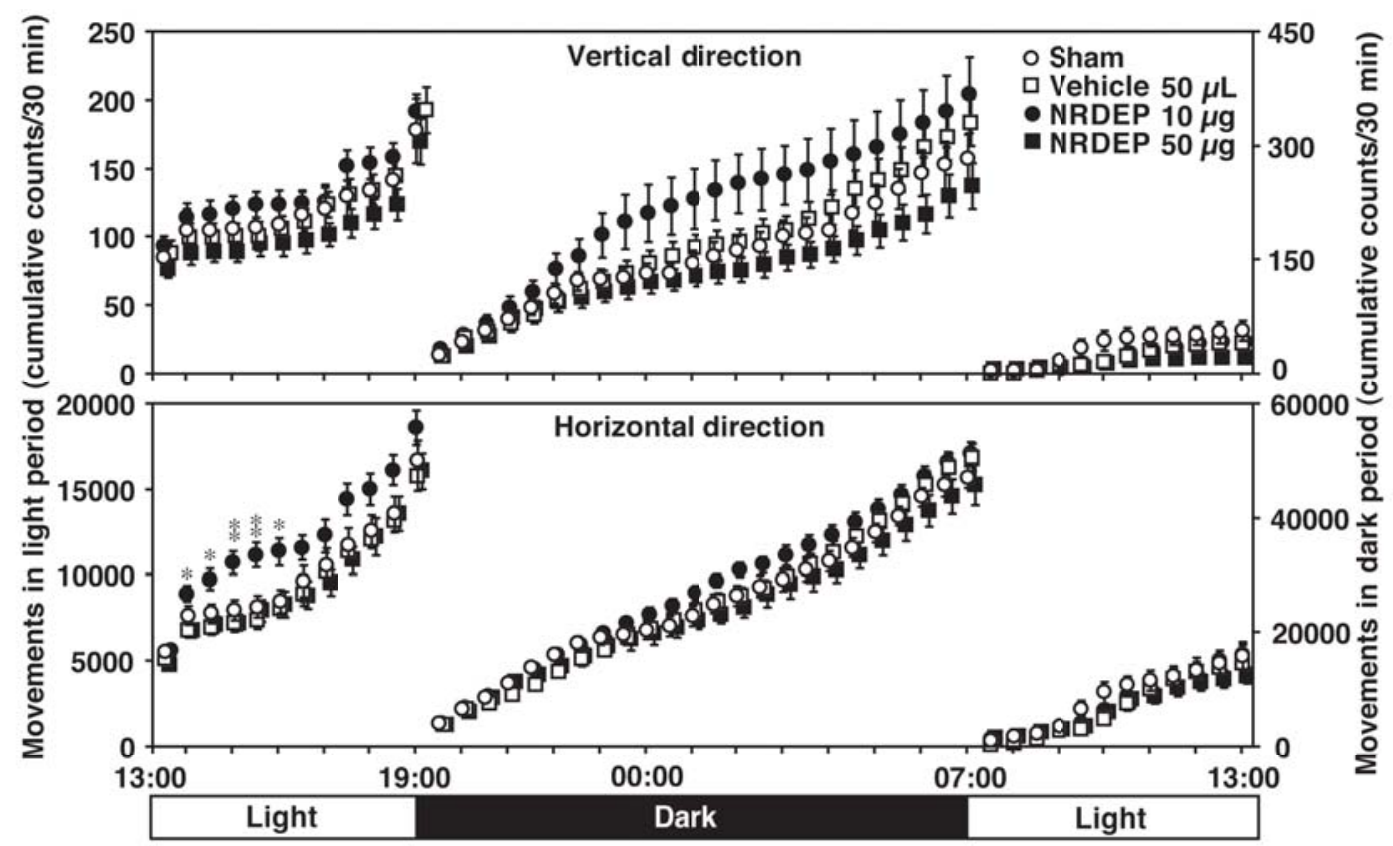

Fig. 1. Spontaneous motor activity in animals measured by Supermex at 6 weeks of age. The spontaneous motor activity of the animals was automatically measured for 30-min intervals over a 24-hr period using Supermex. The cumulative counts of movements in rearing and ambulation at each interval are indicated in the upper and lower panels, respectively. Also, the scales for the counts during the light and dark periods are indicated on the left and right sides, respectively. Data are expressed as means \pm S.E.M. of the 10 animals in each treatment group. $* p<0.01, * * p<0.001$, significantly different from the mean values in the vehicle treatment group (by Bonferroni's post-hoc test).
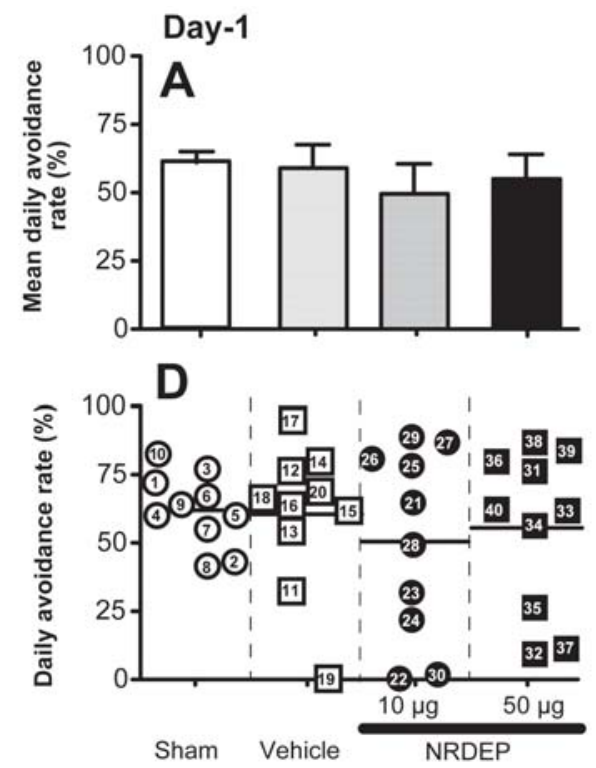

Day-2
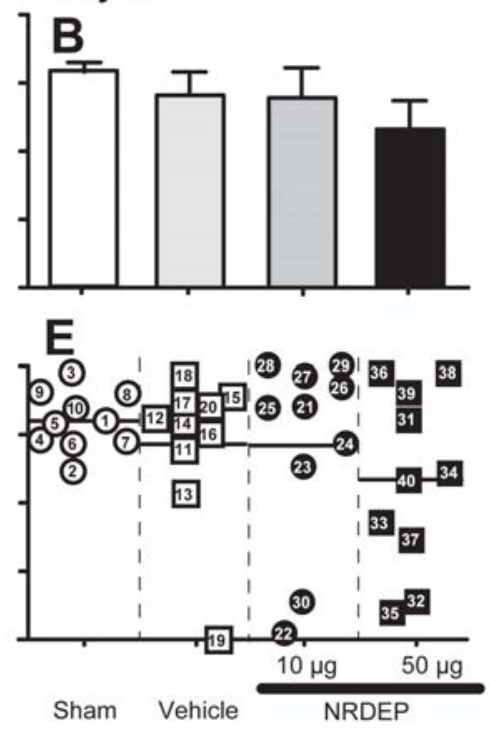

Day-3

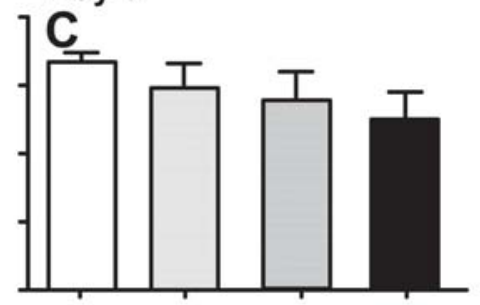

$\mathbf{F}$

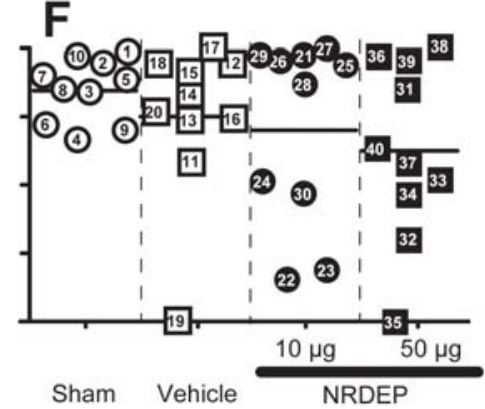

Fig. 2. Changes in daily avoidance rate of the animals subjected to shuttle box tests for 3 consecutive days at 9 weeks of age. Mean daily avoidance rate of each group is shown in the upper panels. Data are expressed as means \pm S.E.M. of the 10 animals in each treatment group. Scatter plots of each group are shown in the lower panels. Bars indicate the average of each group. Numbers in symbols indicate animal number. 
Table 1. The number of animals in each treatment group below the first quartile (the 25th percentile; Q1) of all animals examined (10 out of 40 animals).

\begin{tabular}{llcc}
\hline & Treatments & $\begin{array}{c}\text { Number of } \\
\text { animals }\end{array}$ & $\begin{array}{c}P \text { value } \\
\text { (versus vehicle) }\end{array}$ \\
\hline Day-1 & Sham & 1 & 0.5000 \\
& Vehicle $50 \mu \mathrm{l}$ & 2 & - \\
& NRDEP $10 \mu \mathrm{g}$ & 4 & 0.3142 \\
& NRDEP $50 \mu \mathrm{g}$ & 3 & 0.5000 \\
Day-2 & Sham & & \\
& Vehicle $50 \mu \mathrm{l}$ & 2 & 0.5000 \\
& NRDEP $10 \mu \mathrm{g}$ & 2 & - \\
& NRDEP $50 \mu \mathrm{g}$ & 5 & 0.7090 \\
& & & 0.1749 \\
Day-3 & Sham & 0 & 0.5000 \\
& Vehicle $50 \mu \mathrm{l}$ & 1 & - \\
& NRDEP $10 \mu \mathrm{g}$ & 4 & 0.1517 \\
& NRDEP $50 \mu \mathrm{g}$ & 5 & 0.0704 \\
\hline
\end{tabular}

Q1 $(n=10)$ was calculated from the avoidance performances in all animals examined $(n=40)$. After that, the animals in each group below Q1 were counted. At Day- 3, the animals displaying a lower avoidance ratio than Q1 were mostly observed in the NRDEP-treated animals.

\section{Neurotransmitter levels in brain areas}

Results are summarized in Fig. 4. Neurotransmitter levels of brain areas varied widely by area. In some combinations of area and monoamines or its metabolite, such as NE in VMH, DA and DOPAC in MM, HVA in MM and 5-HT in MM, neurotransmitter levels in the vehicle group were greatly different from those in the sham-treatment group, although a statistical significance between these two groups was not observed. The average of only two samples was used for the HVA levels in VMH because the amount of HVA in 3 of the samples was below the lower limit (0.1 ng/injection), i.e., the samples from the groups treated with $10 \mu \mathrm{g}$ of NRDEP or the vehicle and the group given sham treatment. In MM, DA levels in the animals treated with $10 \mu \mathrm{g}$ of NRDEP tended to be decreased (Fig. 4B). Also, DOPAC and HVA levels in MM in the NRDEP-treated animals tended to be decreased (Figs. 4C and D). However, significant decreases of DA and DOPAC levels were only observed in MM in the NRDEP-treated animals when compared with the animals given sham treatment. Also, 5-HT level in MM in the animals treated with $10 \mu \mathrm{g}$ of NRDEP tended to be decreased (Fig. 4E).
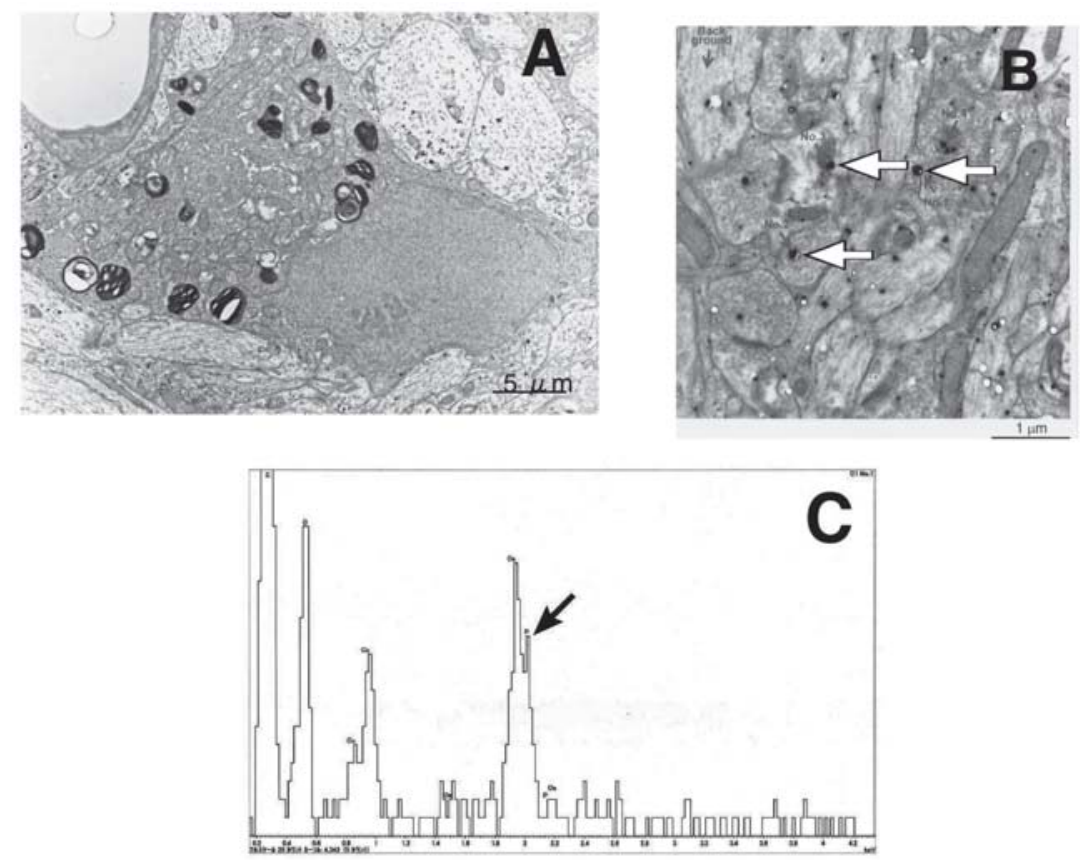

Fig. 3. Histopathological observations in the olfactory bulbs of animals treated intranasally with $50 \mu \mathrm{g}$ of NRDEP. (A) Electron dense lamellar bodies were observed in the microglial cells of the glomerulus (by transmission electron microscopy, scale indicates $5 \mu \mathrm{m}$ ). (B) The accumulation of electron dense granules (arrows) with a diameter of approximately $20 \mathrm{~nm}$ was observed in the axonal cytosole (by transmission electron microscopy, scale indicates $1 \mu \mathrm{m}$ ). (C) Representative result of analysis using energy dispersive X-ray spectroscope. Large granules containing phosphorus were observed. 
The effects of nanoparticle-rich diesel exhaust particles on CNS
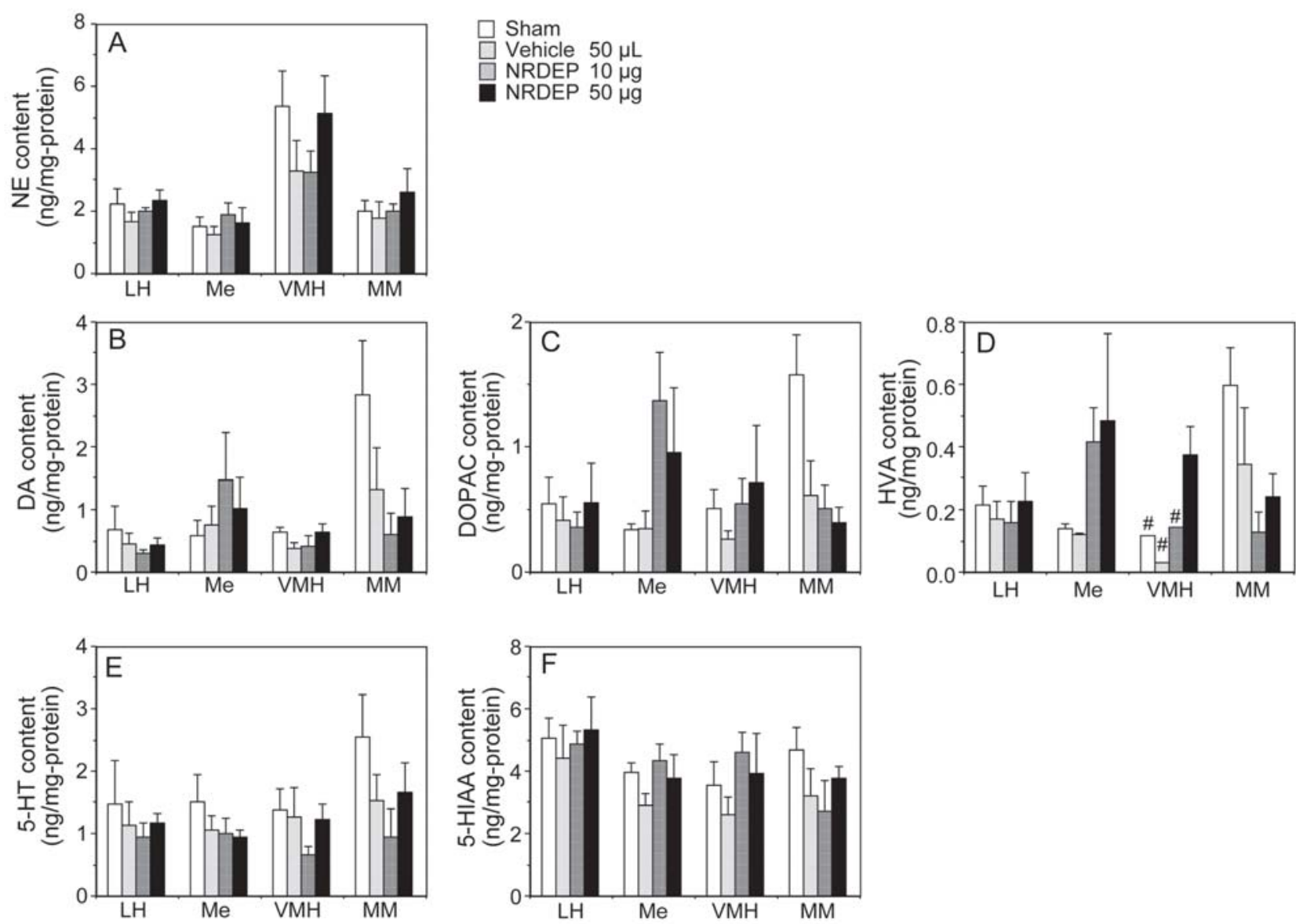

Fig. 4. Monoamine neurotransmitter levels in the brain areas at 14 weeks of age Areas measured were LH, Me, VMH and MM. Also, neurotransmitters and its metabolites measured were DOPAC, 5-HIAA, DA, HVA, NA, 5-HT. Data are expressed as means \pm S.E.M. of 5 animals in each treatment group, except HVA in VMH (\# in panel D: $n=2$ ). Statistical differences were not observed in mean values between the vehicle group and the NRDEP-treated groups (by Bonferroni's post-hoc test).

\section{DISCUSSION}

In biochemical and pathological examinations, the changes observed in the NRDEP-treated animals were not clear. Therefore, it is difficult to explain the mechanisms underlying the changes observed in behavioral examinations, based on the effects on the central nervous system. However, NRDEP subtly affected the emotionality and learning capability of rats in the present study.

Kaur et al. (2005) reported that personal exposure to ultrafine particles at the center of London, an urban area, was in the range of 60,000-100,000 particles $/ \mathrm{cm}^{3}$. Also, in general, human daily respiratory volume is considered to be $20 \mathrm{~m}^{3}$ (Andelman, 1985). From this information, it is considered that the amount of daily personal inhala- tion of ultrafine particles is approximately 36-60 $\mu \mathrm{g} /$ day (1.2-2.0 x $10^{12} \mathrm{particles} /$ day or $0.5-0.9 \mu \mathrm{g} / \mathrm{kg}$; if human body weight is assumed to be $70 \mathrm{~kg}$ ). From these calculations, the doses used in the present study were very high. However these were judged to be reasonable, since the instillation of NRDEP was only performed 4 times. In addition, using of large amounts of test substances in experiments is frequently done to elucidate hidden adverse effects or novel mechanisms of toxicity.

In the active avoidance test using a shuttle box, daily improvements of avoidance performance were observed in the animals given sham treatment and vehicle. However, failure of daily improvement was observed in 4 and 6 animals in the groups treated with 10 and $50 \mu \mathrm{g}$ of NRDEP, respectively. Furthermore, the avoidance rate 
of animals treated with NRDEP was divided into two extremes, "excellent" and "poor." Consequentially, almost all of the animals under the first quartile were NRDEPtreated animals.

A very important question that remained was why the suppression in avoidance performance was only observed in approximately half of the animals treated with NRDEP. It is possible that the distribution of particles in the brain is individually different. Wang et al. (2008a) observed translocation of nano-sized $\mathrm{TiO}_{2}$ by iNI into the hippocampus, a component related to learning and memory functions. The $\mathrm{TiO}_{2}$ content in the hippocampus at 30 days of treatment indicated large differences. This may be the cause for the different effects on the learning and memory functions observed in the animals.

The spontaneous motor activity in the animals treated with $10 \mu \mathrm{g}$ of NRDEP was significantly increased during the initial $3 \mathrm{hr}$ of the measurement, while that in the animals treated with $50 \mu \mathrm{g}$ tended to decrease. The measurement of spontaneous motor activity of the animals was carried out early in the post-administration period. It is possible that iNI of small amounts of NRDEP caused injury mainly in $\mathrm{OB}$ at an early stage without marked injuries in the brain. OB is not only a primary center of olfaction but also a ruler of emotions and learning in animals (Ueki et al., 1972; Leonard, 1984; Durand et al., 1998). It was reported that olfactory bulbectomy caused imbalances in brain neurotransmitters, including noradrenalin, dopamine and serotonin (Edwards et al., 1977; Song and Leonard, 2005), and also caused marked and sustained hyperactivity in rats (van Riezen and Leonard, 1990). Taken together, this information and the present results, it is possible that a small amount of NRDEP enhanced spontaneous activity of the animals through its proinflammatory activity on OB.

Conversely, a high dose of NRDEP $(50 \mu \mathrm{g})$ tended to suppress spontaneous activity. In the measurement of neurotransmitter levels in brain areas, the levels of DA and its metabolites in NRDEP-treated animals tended to decrease in MM. This might have caused the suppression of emotionality in the animals. However, the effects of NRDEP were examined by only two dose levels in the present study. To reveal the effects of high and low dose levels, examination using 4 or more dose levels are necessary.

A tendency to reduced levels of DA and its metabolite, DOPAC, in the MM was observed in the NRDEP-treated animals examined at 14 weeks of age. Block et al. (2004) reported selective toxicity of nano-sized DEP to dopaminergic neurons in vitro in co-culture with microglia. Initially, glial cells phagocytized nano-sized DEP, then the dopaminergic neurons were injured by reactive oxygen species, which were produced by the glial cells.

Because of the lower content of glutathione, an antioxidant tripeptide, dopaminergic neurons are less resistant to oxidative stress than other types of neurons, such as GABAnergic neurons. Therefore, the decrease in DA level in the brain might be involved in the behavioral changes, such as suppression of the spontaneous motor activity in $50 \mu \mathrm{g}$-NRDEP-group and failure in the avoidance task in both, NRDEP-groups. Thus, a lowered content of DA and DOPAC in MM in the present study looks like a reasonable result.

However, similar tendencies in DA and DOPAC content were also observed in vehicle-treated animals. It is difficult to explain why iNI of the vehicle $(0.05 \%$ Tween 80 -saline solution) changed neurotransmitter levels in the brain areas. Since Tween 80 was reported to have a low cytotoxicity (Arechabala et al., 1999), it is inconceivable that iNI of the vehicle injured OB or the brain. The measured areas of the brain in the present study were only 4 areas. Thus, it is possible that NRDEP suppressed avoidance performance by injuring other areas of the brain, which were not measured in the present study, such as the striatum. In addition, it is also possible that iNI of the vehicle moistened the nasal cavity and caused, thereby, deposition of small dust particles from the bedding chips or feces. However, to clarify these hypotheses, further examination is necessary.

It was reported that hyperactivity of bulbectomized rats was abolished or attenuated when the animals were placed in an area surrounded by transparent walls (Kelly et al., 1997). The spontaneous motor activity of the animals was measured in a clear acrylic cage in the present study. This might, therefore, have attenuated the enhancement of spontaneous motor activity in the animals. For this reason, it is considered that further study by other methods, such as an open-field test, is necessary to evaluate the effects on spontaneous motor activity of NRDEP by iNI. Also, the animals were placed in a novel environment during the measurement, different from their home cages (stainless steel grid-floor cages). In general, spontaneous motor activity during the initial period in a novel environment is high, since the animal exhibits exploratory behavior (Takeda et al., 2005). Increased motor activity in the animals treated with $10 \mu \mathrm{g}$ of NRDEP might represent enhanced emotionality related to exploration.

An examination for translocation of NRDEP was made by energy dispersive X-ray spectroscopy in the 5-week old animals, and no marked evidence was found in the present study. Since the amount of metals, such as Fe, Ni, $\mathrm{Cu}$ or $\mathrm{Zn}$, contained in NRDEP was very low, specifica- 
The effects of nanoparticle-rich diesel exhaust particles on CNS

tion of the NRDEP in the small field of specimens was very difficult. However the accumulations of lamella in microglia and of phospholipid granules in neuronal axons in the glomerular layer in the main OB were observed by electronmicroscopy at 5 weeks of age. From these facts and the results, it was considered that our present result does not deny the translocation of NRDEP into the OB.

In the present study, the weights of organs in the animals treated with NRDEP were not different from those in the animals given sham treatment or treated with the vehicle. It was reported that DEP contains various chemicals, including endocrine-disrupting chemicals (Izawa et al., 2007). Since no differences were observed in the weights of testes and adrenal glands, involvement of an endocrine-disrupting effect of NRDEP in the present study was negligible.

Several environmental factors that might affect emotionality, temperament, learning capability or cognitive function in children were considered (Rush and Callahan, 1989; Brouillette and Quirion, 2008; Ljung et al., 2009). Although the effects of NRDEP observed in the present study were very slight, the substance might be one of those environmental factors. Even if the adverse effects of individual environmental pollutants are slight, a combination of pollutants could obviously affect a child's life.

In conclusion, the present results suggest that NRDEP potentially affects emotionality and learning capability in animals in later life via modulation of monoamine neurotransmitter levels in CNS.

\section{ACKNOWLEDGMENTS}

The authors thank professors Dr. Konosuke Kumakura and Dr. Nobuyuki Sasakawa (Info. \& Commun. Sci., Sophia Univ.), and Dr. Masanobu Yoshikawa (Clin. Pharmacol., Tokai Univ.) for their technical advices in the present study.

The authors also thank to RIX Co., Ltd. and Hitachi High-Technologies Co. for their skilful assistances in the measurement of brain monoamine content by high-sensitive electrochemical detector and in the analysis by energy dispersive X-ray spectroscope.

\section{REFERENCES}

No authors listed. (1997): Declaration of the environment leaders of the Eight on children's environmental health. Can. J. Public Health, 89, Suppl. 1, S5-S9.

Andelman, J.B. (1985): Human exposures to volatile halogenated organic chemicals in indoor and outdoor air. Environ. Health Perspect., 62, 313-318.

Arechabala, B., Coiffard, C., Rivalland, P., Coiffard, L.J. and de
Roeck-Holtzhauer, Y. (1999): Comparison of cytotoxicity of various surfactants tested on normal human fibroblast cultures using the neutral red test, MTT assay and LDH release. J. Appl. Toxicol., 19, 163-165.

Biswas, P. and Wu, C.Y. (2005): Nanoparticles and the environment. J. Air Waste Manag. Assoc., 55, 708-746.

Block, M.L., Wu, X., Pei, Z., Li, G., Wang, T., Qin, L., Wilson, B., Yang, J., Hong, J.S. and Veronesi, B. (2004): Nanometer size diesel exhaust particles are selectively toxic to dopaminergic neurons: the role of microglia, phagocytosis, and NADPH oxidase. FASEB J., 18, 1618-1620.

Brouillette, J. and Quirion, R. (2008): The common environmental pollutant dioxin-induced memory deficits by altering estrogen pathways and a major route of retinol transport involving transthyretin. Neurotoxicology, 29, 318-327.

Calderón-Garcidueñas, L., Franco-Lira, M., Henríquez-Roldón, C., Osnaya, N., González-Maciel, A., Reynoso-Robles, R., Villarreal-Calderon, R., Herritt, L., Brooks, D., Keefe, S., Palacios-Moreno, J., Villarreal-Calderon, R., Torres-Jardón, R., Medina-Cortina, H., Delgado-Chávez, R., Aiello-Mora, M., Maronpot, R.R. and Doty, R.L. (2010): Urban air pollution: Influences on olfactory function and pathology in exposed children and young adults. Exp. Toxicol. Pathol., 62, 91-102.

Durand, M., Coronas, V., Jourdan, F. and Quirion, R. (1998): Developmental and aging aspects of the cholinergic innervation of the olfactory bulb. Int. J. Dev. Neurosci., 16, 777-785.

Edwards, D.A., Schlosberg, A.J., McMaster, S.E. and Harvey, J.A. (1977): Olfactory system damage and brain catecholamines in the rat. Brain Res., 121, 121-130.

Fujitani, Y., Hirano, S., Kobayashi, S., Tanabe, K., Suzuki, A., Furuyama, A. and Kobayashi, T. (2009): Characterization of dilution conditions for diesel nanoparticle inhalation studies. Inhal. Toxicology, 21, 200-209.

Ito, K. and Thurston, G.D. (1996): Daily PM10/mortality associations: an investigations of at-risk subpopulations. J. Expo. Anal. Environ. Epidemiol., 6, 79-95.

Izawa, H., Kohara, M., Watanabe, G., Taya, K. and Sagai, M. (2007): Diesel exhaust particle toxicity on spermatogenesis in the mouse is aryl hydrocarbon receptor dependent. J. Reprod. Dev., 53, 1069-1078.

Kaur, S., Nieuwenhuijsen, M. and Colvile, R. (2005): Personal exposure of street canyon intersection users to $\mathrm{PM}_{2.5}$, ultrafine particle counts and carbon monoxide in central London, UK. Atmospheric Environment, 39, 3629-3641.

Kelly, J.P., Wrymn, A.S. and Leonard, B.E. (1997): The olfactory bulbectomized rat as a model of depression: an update. Pharmacol. Ther., 74, 299-316.

Leonard B.E. (1984): The olfactory bulbectomized rat as a model of depression. Pol. J. Pharmacol. Pharm., 36, 561-569.

Liu, Y., Gao, Y., Zhang, L., Wang, T., Wang, J., Jiao, F., Li, W., Liu, Y., Li, Y., Li, B., Chai, Z., Wu, G. and Chen, C. (2009): Potential health impact on mice after nasal instillation of nano-sized copper particles and their translocation in mice. J. Nanosci. Nanotechnol., 9, 6335-6343.

Ljung, R., Söqvist, P. and Hygge, S. (2009): Effects of road traffic noise and irrelevant speech on children's reading and mathematical performance. Noise Health, 11, 194-198.

Mistry, A., Glud, S.Z., Kjems, J., Randel, J., Howard, K.A., Stolnik, S. and Illum, L. (2009): Effect of physicochemical properties on intranasal nanoparticle transit into murine olfactory epithelium. J. Drug Target., 17, 543-552.

Neas, L.M., Dockery, D.W., Koutrakis, P., Tollerud, D.J. and 
S. Yokota et al.

Speizer, F.E. (1995): The association of ambient air pollution with twice daily peak expiratory flow rate measurements in children. Am. J. Epidemiol., 141, 111-122.

Oberdörster, G., Maynard, A., Donaldson, K., Castranova, V., Fitzpatrick, J., Ausman, K., Carter, J., Karn, B., Kreyling, W., Lai, D., Olin, S., Monteiro-Riviere, N., Warheit, D. and Yang, H.; ILSI Research Foundation/Risk Science Institute Nanomaterial Toxicity Screening Working Group. (2005): Principles for characterizing the potential human health effects from exposure to nanomaterials: elements of a screening strategy. Part. Fibre Toxicol., 6, 2-8.

Palkovits, M. and Brownstein, M. (1983): Microdissection of brain areas by the punch technique. In Brain microdissection techniques (Cuello, A.C., ed.), pp.1-36. A Wiley Intersci.

Paxinos, G. and Watson, C. (1998): The rat brain in stereotaxic coordinates. Academic Press.

Rich, D.Q., Schwartz, J., Mittleman, M.A., Link, M., LuttmannGibson, H., Catalano, P.J., Speizer, F.E. and Dockery, D.W. (2005): Association of short-term ambient air pollution concentrations and ventricular arrhythmias. Am. J. Epidemiol., 161, 1123-1132.

Rush, D. and Callahan, K.R. (1989): Exposure to passive cigarette smoking and child development. A critical review. Ann. N Y Acad. Sci., 562, 74-100.

Saito, Y., Usumi, K., Nagata, T., Marumo, H., Imai, K. and Kato, M. (1997): Early changes in the rat testis induced by di-(2-ethylhexyl) phthalate and 2, 5-hexanedione -ultrastructure and lanthanum trace study-. J. Toxicol. Pathol., 10, 51-57.

Song, C. and Leonard, B.E. (2005): The olfactory bulbectomised rat as a model of depression. Neurosci. Biobehav. Rev., 29, 627647.

Suglia, S.F., Gryparis, A., Wright, R.O., Schwartz, J. and Wright, R.J. (2008): Association of black carbon with cognition among children in a prospective birth cohort study. Am. J. Epidemiol., 167, 280-286.

Takeda, H., Tsuji, M., Ikoshi, H., Yamada, T., Masuya, J., Iimori, M. and Matsumiya, T. (2005): Effects of a 5-HT 7 receptor antagonist DR4004 on the exploratory behavior in a novel environment and on brain monoamine dynamics in mice. Eur. J.
Pharmacol., 518, 30-39.

Ueki, S., Nurimoto, S. and Ogawa, N. (1972): Effects of psychotropic drugs on emotional behavior in rats with limbic lesions, with special reference to olfactory bulb ablations. Folia Psychiatr. Neurol. Jpn., 26, 245-255.

van Riezen, H. and Leonard, B.E. (1990): Effects of psychotropic drugs on the behavior and neurochemistry of olfactory bulbectomized rats. Pharmacol. Ther., 47, 21-34.

Vogl, G. and Elstner, E.F. (1989): Diesel soot particles catalyze the production of oxy-radicals. Toxicol. Lett., 47, 17-23.

Wang, J., Chen, C., Liu, Y., Jiao, F., Li, W., Lao, F., Li, Y., Li, B., Ge, C., Zhou, G., Gao, Y., Zhao, Y. and Chai, Z. (2008a): Potential neurological lesion after nasal instillation of $\mathrm{TiO}_{2}$ nanoparticles in the anatase and rutile crystal phases. Toxicol. Lett., 183, 72-80.

Wang, J., Liu, Y., Jiao, F., Lao, F., Li, W., Gu, Y., Li, Y., Ge, C., Zhou, G., Li, B., Zhao, Y., Chai, Z. and Chen, C. (2008b): Time-dependent translocation and potential impairment on central nervous system by intranasally instilled $\mathrm{TiO}_{2}$ nanoparticles. Toxicology, 254, 82-90.

Win-Shwe, T.T., Yamamoto, S., Ahmed, S., Kakeyama, M., Kobayashi, T. and Fujimaki, H. (2006): Brain cytokine and chemokine mRNA expression in mice induced by intranasal instillation with ultrafine carbon black. Toxicol. Lett., 163, 153160.

Win-Shwe, T.T., Mitsushima, D., Yamamoto, S., Fukushima, A., Funabashi, T., Kobayashi, T. and Fujimaki, H. (2008a): Changes in neurotransmitter levels and proinflammatory cytokine mRNA expressions in the mice olfactory bulb following nanoparticle exposure. Toxicol. Appl. Pharmacol., 226, 192-198.

Win-Shwe, T.T., Yamamoto, S., Fujitani, Y., Hirano, S. and Fujimaki, H. (2008b): Spatial learning and memory functionrelated gene expression in the hippocampus of mouse exposed to nanoparticle-rich diesel exhaust. Neurotoxicology, 29, 940-947.

Wong, T.W., Lau, T.S., Yu, T.S., Neller, A., Wong, S.L., Tam, W. and Pang, S.W. (1999): Air pollution and hospital admissions for respiratory and cardiovascular diseases in Hong Kong. Occup. Environ. Med., 56, 679-683. 